\title{
Modeling of Spray-Formed Plates Using an X-Y Moving Substrate
}

\author{
Y.J. LIN, W. FENG, J.E. BOBROW, and E.J. LAVERNIA
}

\begin{abstract}
A mathematical model, incorporating the thermal component of sticking efficiency $\left(S E_{t}\right)$ into the calculation of shape evolution, is formulated to predict the evolution and final geometry of plates. The plates are spray formed using a moving substrate displaced in a two-dimensional (i.e., $X-Y$ ) plane. By using this model, the effects of the substrate movement parameters, such as the acceleration, time required to complete a stroke in the reciprocal movement direction ( $X$-axis), and the velocity in the uniform movement direction ( $Y$-axis), on the shapes of the plates are investigated. The processing parameters are evaluated by minimizing the values of the mean-squared $(M S)$ surface roughness. On the basis of the evaluation, the optimal combinations of processing parameters are found.
\end{abstract}

\section{INTRODUCTION}

AS a near-net-shape manufacturing technique, spray forming is used to commercially fabricate billets, rolls, and pipes, and it is being developed to produce plates in industrial scales. $^{[1,2]}$ In order to attain this goal, several mathematical models have been established to predict the final geometry of plates and to investigate the effects of processing parameters on the shapes of plates.

Tsao and Grant ${ }^{[3]}$ developed mathematical formulations to describe and predict the distribution of spray density and the morphologies and yields of spray-formed plates, using ultrasonic gas atomization circular and linear atomizers with various substrate manipulation strategies, including stationary and moving substrates. In References 4 and 5, flat plates were produced with a moving substrate and a scanning atomizer along the plane perpendicular to the moving direction of the substrate. In related work, Oh and Lee ${ }^{[6]}$ established a mathematical formulation to investigate the thickness and surface roughness of manufactured plates with different combinations of processing parameters, such as the traveling velocity of the atomizer, the moving velocity of the substrate, and the deposition rate. However, the aforementioned models considered the sticking efficiency - the ratio of droplets incorporated into the deposit's surface to all those impinging on its surface-as unity. In most practical situations, a portion of the droplets fail to remain in the deposit's surface and, hence, the sticking efficiency is less than unity. Moreover, all of these models assume that the deposited material grows only along the thickness direction. Actually, the growth at any point in the deposit occurs along the normal direction of the surface at that particular point. ${ }^{[7]}$

In this article, a mathematical model is formulated and implemented to predict the evolution and final geometry of plates of tool steel A2 that are generated using a substrate that is displaced on a plane (i.e., $X-Y$ ). The mathematical

Y.J LIN, Graduate Student, and E.J. LAVERNIA, Professor, Department of Chemical and Biochemical Engineering and Materials Science, J.E. BOBROW, Professor, Department of Mechanical and Aerospace Engineering, and W. FENG, Research Associate, Department of Mechanical and Aerospace Engineering and the Department of Chemical and Biochemical Engineering and Materials Science, are with the University of California Irvine, Irvine, CA 92697.

Manuscript submitted June 7, 2000. approach is described as follows. First, formulas to calculate the growth rate of any point on the plates' surface are described. The sticking efficiency $(S E)$, whose thermal component $S E_{t}$ represents the effect of heat transfer on the buildup of the deposit's shape, is incorporated into the calculation. In order to determine $S E_{t}$, the liquid fraction in the spray $\left(f_{l, s}\right)$ is calculated by analyzing the dynamics and cooling history of single droplets, while the liquid fraction on the deposit's surface $\left(f_{l, d}\right)$ is assumed to be equal to the liquid fraction in the spray during the entire spray forming, due to the high heat resistance of the ceramic substrate. Second, a numerical simulation of the deposition process is performed in order to determine the new surface of the deposit. On the basis of the computational results, the effects of the movement parameters of the $X-Y$ moving substrate, such as the acceleration and stroke time in the reciprocal movement direction ( $X$-axis) and the velocity in a uniform movement direction ( $Y$-axis), on the shape of the plates are investigated. The surface roughness of the plates and the deposition yield are introduced to evaluate the processing parameters and to find their optimal combinations.

\section{DESCRIPTION OF THE SPRAY-FORMING MODE}

As shown in Figure 1, the following spray mode is employed. (1) During spray forming, the atomizer is maintained at a fixed height location with respect to the vertical $Z$-axis. (2) The planar substrate moves in two directions perpendicular to each other in a horizontal plane. In the $Y$ direction, it moves at a uniform velocity $(V)$. In the $X$ direction, it reciprocates with stroke $(S)$, acceleration and deceleration $(A)$, and the stroke time $(T)$. At the beginning of spray forming, the atomizer is located at a position such that the spray axis of the atomizer passes through the origin $(x=0$ and $y=0$ ). For convenience purposes, assume that the substrate is fixed and the atomizer moves in the opposite direction of the substrate movement, both in the $X$-axis and the $Y$-axis. A standard trapezoidal velocity profile is used to define the motion in the reciprocating $X$ direction in this study (Figure 2).

The $X$-direction motion is defined by the following.

(1) A period of constant acceleration, $\dot{V}_{x}=A$, for $t_{e} \leq t_{a}$, 


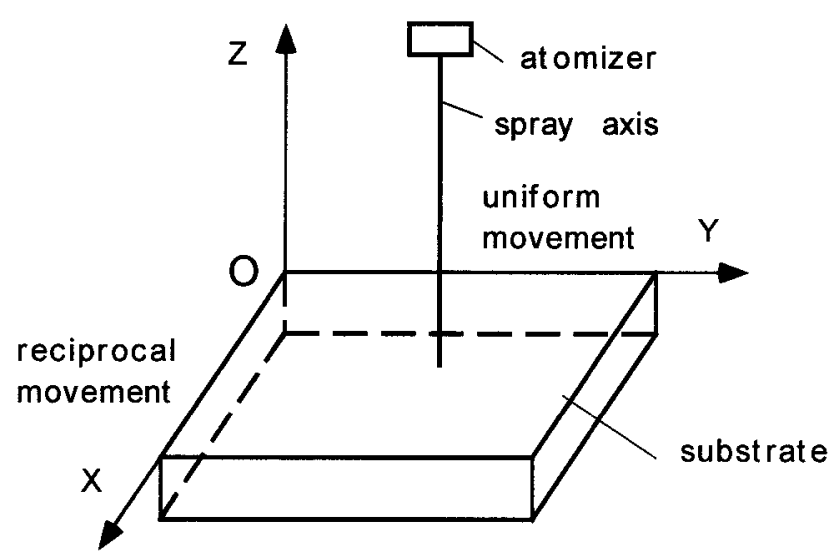

Fig. 1-Spray mode and Cartesian coordinate system used in the study.

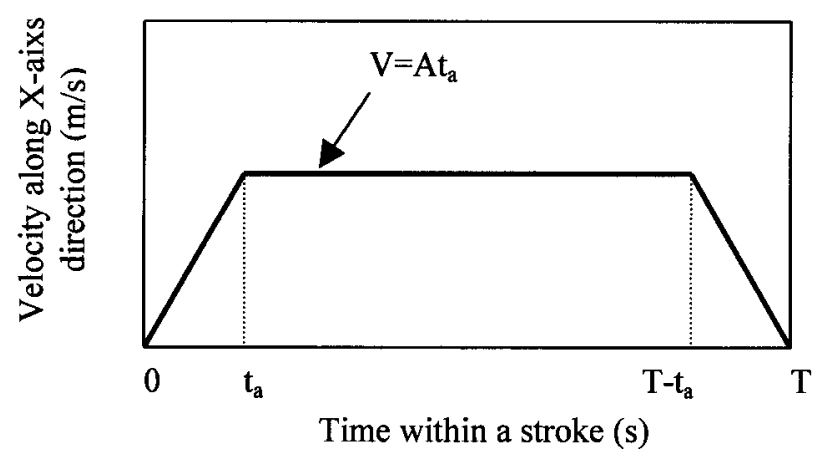

Fig. 2-Standard trapezoidal velocity profile-X direction motion.

where $A$ is the acceleration and $t_{e}$ is the time within a stroke, $t_{e}<T$.

(2) A period of constant velocity, $V_{x}=A t_{a}$, for $t_{a} \leq t_{e} \leq$ $T-t_{a}$.

(3) A period of constant deceleration, $\dot{V}_{x}=-A$, for $t_{e} \geq$ $T-t_{a}$.

The acceleration time $\left(t_{a}\right)$ is given by

$$
t_{a}=\frac{T}{2}-\sqrt{\frac{T^{2}}{4}-\frac{S}{A}}
$$

At any time, $t=N \cdot T+t_{e}$ (where $N$ is a positive integer and $\left.t_{e}<T\right)$. The Cartesian coordinates of the atomizer $\left(x_{a}\right.$, $y_{a}, z_{a}$ ) are calculated from the following equation:

$x_{a}= \begin{cases}\left(1-(-1)^{N}\right) \cdot S+\frac{(-1)^{N} \cdot A t_{a}^{2}}{2} & t \leq t_{a} \\ \left(1-(-1)^{N}\right) \cdot S+\frac{(-1)^{N} \cdot A t_{a} \cdot\left(2 t_{e}-t_{a}\right)}{2} & t_{a}<t<\left(T-t_{a}\right) \\ \left(1-(-1)^{N}\right) \cdot S+\frac{(-1)^{N} \cdot A \cdot\left(2 T t_{e}+2 T t_{a}-2 t_{a}^{2}-t_{e}^{2}-T^{2}\right)}{2} & t_{e} \geq\left(T-t_{a}\right)\end{cases}$

$y_{a}=V t$

$z_{a}=h_{a}$

\section{MATHEMATICAL MODEL}

\section{A. Growth Rate at a Point of the Plate Surface}

The growth rate at a point $P\left(x_{p}, y_{p}, z_{p}\right)$ of the plate surface $(H)$ is determined by the following equation: $:^{[8]}$

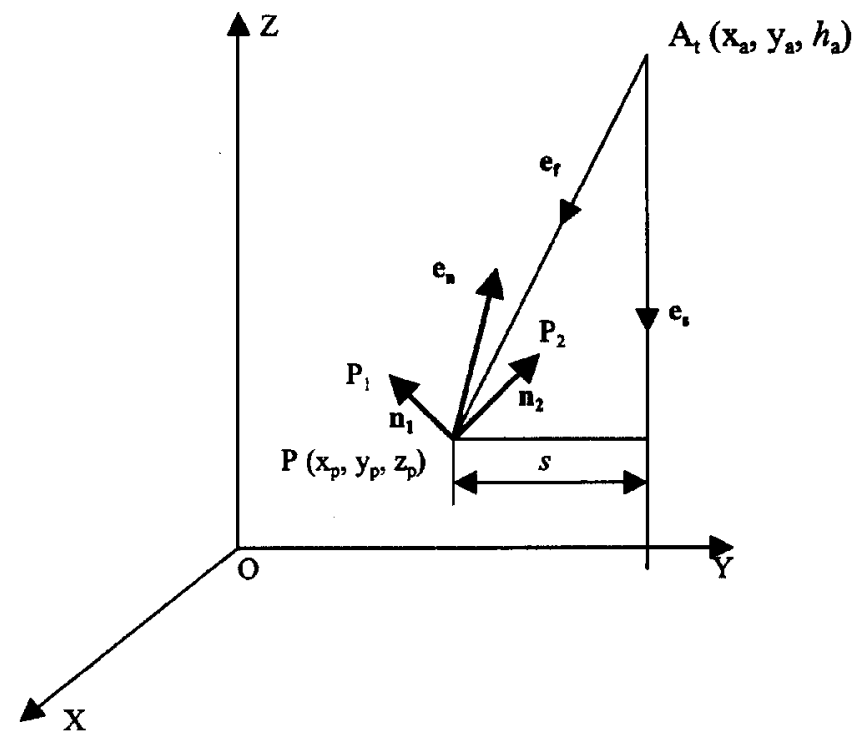

Fig. 3-Schematic diagram for calculation of the growth rate at a point $P$ of the plate surface.

$$
H=H_{g} \cdot S E
$$

where $H\left(\mathrm{~mm}^{3} \cdot \mathrm{mm}^{-2} \cdot \mathrm{s}^{-1}\right)$ is the growth rate in a point of the plate surface, $H_{g}\left(\mathrm{~mm}^{3} \cdot \mathrm{mm}^{-2} \cdot \mathrm{s}^{-1}\right)$ is the deposition rate from the spray, and $S E$ is the sticking efficiency.The term $H_{g}$ is given from the following equation: ${ }^{[9]}$

$$
H_{g}=\left|\frac{\mathbf{e}_{n} \cdot \mathbf{e}_{f}}{\mathbf{e}_{s} \cdot \mathbf{e}_{f}}\right| \cdot \xi \cdot a \cdot \exp \left(-b \cdot s^{2}\right)
$$

Where $\mathbf{e}_{n}$ is the unit normal vector of plate surface at the point $P, \mathbf{e}_{s}$ is the unit vector in the direction of the spray axis, and $\mathbf{e}_{f}$ is the unit vector in the flight direction of the droplets toward the point $P$. The variables $a, b, s$, and $\xi$ will be defined in the following text. Assuming that the position vector of the atomizer $A_{t}$ is $\mathbf{a}_{t}$ (Figure 3 ), then

$$
\mathbf{e}_{f}=\frac{P-\mathbf{a}_{t}}{\left\|P-\mathbf{a}_{t}\right\|}
$$

Assuming that $P_{1}=\left(x_{p 1}, y_{p 1}, z_{p 1}\right)$ and $P_{2}=\left(x_{p 2}, y_{p 2}, z_{p 2}\right)$ are two points on the surface very near $P$, and that $n_{1}=$ $\mathbf{P P}_{1}$ and $n_{2}=\mathbf{P P}_{2}, \mathbf{n}_{1}$ and $\mathbf{n}_{2}$ spanning the tangential plane of the surface at point $P$. Then, the surface normal (Figure 3) is

$$
\mathbf{e}_{n}=\frac{\mathbf{n}_{2} \times \mathbf{n}_{1}}{\left\|\mathbf{n}_{2} \times \mathbf{n}_{1}\right\|}
$$

where $s$ (in millimeters), the parameter in Eq. [4], is the distance between point $P$ and the spray axis, which is given from the following equation (Figure 3):

$$
s^{2}=\left(x_{p}-x_{a}\right)^{2}+\left(y_{p}-y_{a}\right)^{2}
$$

where $a\left(\mathrm{~mm}^{3} \cdot \mathrm{mm}^{-2} \cdot \mathrm{s}^{-1}\right)$ and $b\left(\mathrm{~mm}^{-2}\right)$ are the maximum deposition rate and spray-distribution coefficient at this distance between the atomizer and the plane passing through point $P$ and perpendicular to the spray axis, respectively, which are calculated from the following equations:

$$
a=a_{s}\left(\frac{d_{s}}{h_{a}-z_{p}}\right)^{2}
$$


Table I. Physical and Thermal Properties of Tool Steels A2

\begin{tabular}{ll}
\hline Latent heat of melt, $\Delta H_{f}\left(\mathrm{~J} \cdot \mathrm{kg}^{-1}\right)$ & 280,000 \\
Heat capacity, $C_{p}\left(\mathrm{~J} \cdot \mathrm{kg}^{-1} \cdot \mathrm{K}^{-1}\right)$ & 447 \\
Melt density, $\rho_{m}\left(\mathrm{~kg} \cdot \mathrm{m}^{-3}\right)$ & $7015-0.000883(T-1809)$ \\
Solid density, $\rho_{s}\left(\mathrm{~kg} \cdot \mathrm{m}^{-3}\right)$ & 7800 \\
Equilibrium distribution coeffi- & 0.7 \\
$\quad$ cient, $k_{e}$ & \\
Melting point of pure Fe, $T_{M}\left({ }^{\circ} \mathrm{C}\right)$ & 1536 \\
Liquidus temperature, $T_{l}\left({ }^{\circ} \mathrm{C}\right)$ & 1445 \\
Eutectic temperature, $T_{E}\left({ }^{\circ} \mathrm{C}\right)$ & 1265 \\
Solid-liquid interfacial tension, $\gamma_{s l}$ & 0.204 \\
$\quad\left(\mathrm{~J} \cdot \mathrm{m}{ }^{-2}\right)$ & \\
Surface tension of melt, $\gamma_{m}$ & $1.872-0.00049(T-1809)$ \\
$\quad\left(\mathrm{J} \cdot \mathrm{m}^{-2}\right)$ & \\
Dynamic viscosity of melt, $\mu_{m}$ & $0.3699 \operatorname{exp~}(41,400 / \mathrm{R} T)$ \\
$\quad\left(\mathrm{Ns} \cdot \mathrm{m}^{-2}\right)$ &
\end{tabular}

$$
b=b_{s}\left(\frac{d_{s}}{h_{a}-z_{p}}\right)^{2}
$$

where $d_{s}$ (in millimeters) is the reference distance between the atomizer and the plane perpendicular to the spray axis; $a_{s}\left(\mathrm{~mm}^{3} \cdot \mathrm{mm}^{-2} \cdot \mathrm{s}^{-1}\right)$ and $b_{s}\left(\mathrm{~mm}^{-2}\right)$ are the maximum deposition rate and spray-distribution coefficient at the reference distance, respectively; $h_{a}$ is the atomizer's height away from the substrate's surface; and $z_{p}$ is the $Z$ coordinate of the point $P$.

The term $\xi$ is the shadowing-effect coefficient, which is determined according to the following method: ${ }^{[10]} \mathbf{e}_{n} \cdot \mathbf{e}_{f}<$ $0, \xi=1$; and $\mathbf{e}_{n} \cdot \mathbf{e}_{f} \geq 0, \xi=0$.

The term $S E$ is the product of the geometrical component $S E_{g}$ and the thermal component $S E_{t}$, given from the following equations: ${ }^{[8]}$

$$
\begin{aligned}
S E & =S E_{g} \cdot S E_{t} \\
S E_{g} & =\cos \theta \\
S E_{t} & =\eta_{s} f_{s, s}+\eta_{l} f_{l, s} \\
\eta_{s} & =1-0.75\left(1-f_{l, d}\right) \\
\eta_{l} & =0.98
\end{aligned}
$$

where $\theta$ is the angle between the normal vector of the surface at the point and the flight direction of droplets to the point; $f_{s, s}$ and $f_{l, s}$ represent the fraction of solid and liquid in the spray, respectively; $f_{l, d}$ is the fraction of liquid on the deposit surface at the point; and $\eta_{s}$ and $\eta_{l}$ are the sticking coefficients of the solid and liquid in the spray, respectively.

The value of $S E_{t}$ is determined by the liquid fraction in the spray and on the deposit's surface. In the following text, the formulations for $f_{l, s}$ and $f_{l, d}$ are described. Tool steel A2, with a nominal composition of Fe-1 pet C-5.25 pct $\mathrm{Cr}-0.85$ pet $\mathrm{Mn}-1.1$ pet Mo- 0.25 pet $\mathrm{V}-0.3$ pet $\mathrm{Si}$, and nitrogen are chosen as the model material and atomization gas, respectively. Their thermal and physical properties are listed in Tables I and II. ${ }^{[1,12,13]}$

\section{B. Fraction of Liquid in the Spray and on the Surface of the Plate}

\section{Fraction of liquid in spray}

In the drop's flight direction, at a certain spray distance $(x)$, the fraction of liquid $\left(f_{l, s}(x)\right)$ is obtained from the following equation:
Table II. Physical and Thermal Properties of Atomization $\operatorname{Gas}\left(\mathbf{N}_{2}\right)$

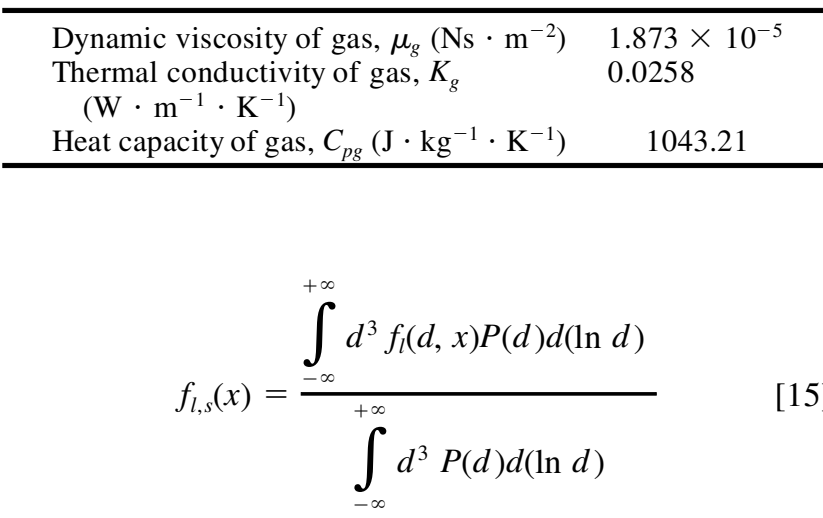

Where $f_{l}(d, x)$ is the liquid fraction of drops with a diameter of $d$ as a function of the spray distance of the point (the distance between the atomizer and the point). The term $P(d)$ is the distribution density of droplets with a diameter of $d$; $P(d)$ is determined from the following equation: ${ }^{[15-18]}$

$$
P(d)=\frac{1}{\sqrt{2 \pi} \ln \sigma_{g}} \exp \left(-\frac{\left(\ln d-\ln d_{m}\right)^{2}}{2\left(\ln \sigma_{g}\right)^{2}}\right)
$$

Where $d_{m}$ and $\sigma_{g}$ are the mass median diameter and geometric standard deviation, respectively. The values of $d_{m}$ and $\sigma_{g}$ are calculated from the following equations: ${ }^{[18,19]}$

$$
\begin{aligned}
d_{m} & =D K\left(\frac{\eta_{m}}{\eta_{g} \mathrm{~W}} \cdot\left(1+\frac{\dot{M}}{G}\right)\right)^{1 / 2} \\
\mathrm{~W} & =\nu^{2} \rho_{m} D / \gamma_{m} \\
\sigma_{g} & =k_{1} d_{m}^{k_{2}}
\end{aligned}
$$

Where $D$ is the melt-stream diameter and $K$ is a constant; $\eta_{m}$ and $\eta_{g}$ are the kinematic viscosity of the melt and gas, respectively; $\dot{M}$ and $\dot{G}$ are the flow rate of the melt and gas, respectively; $\mathrm{W}$ is the Weber number; $v$ is the gas velocity during interaction between the gas jets and the melt stream; $\rho_{m}$ and $\gamma_{m}$ are the density and surface tension of the melt, respectively; and $k_{1}$ and $k_{2}$ are constants, and they are taken to be $k_{1}=0.425$ and $k_{2}=0.333 .^{[19]}$

The term $f_{l}(d, x)$ is related to the dynamics and thermal history of single droplets. The droplet cooling can be described by five cooling stages for tool steel A2, a eutectic alloy: liquid-phase solidification, nucleation and recalescence, segregated solidification, eutectic solidification, and solid-phase solidification. The details are described in Reference 14.

In this study, circular convergent-divergent nozzles are selected, having 18 jets, a total exit area of $16.42 \cdot 10^{-6} \mathrm{~m}^{2}$, and a spray-distribution coefficient $\left(b_{s}\right)$ of $0.0015 \mathrm{~mm}^{-2}$ at a reference distance of $350 \mathrm{~mm}$. The metal flow rate is 0.078 $\mathrm{kg} / \mathrm{s}$ (maximum spray rate is $5 \mathrm{~mm} \cdot \mathrm{s}^{-1}$ ). Figure 4 shows the liquid fraction in the spray as a function of spray distance. In this study, the melt superheat is $100 \mathrm{~K}$ and the $z$-coordinate value of the atomizer is kept at $350 \mathrm{~mm}$ during the whole spray-forming process.

\section{Liquid fraction on the surface of the plate}

The deposition of droplets, initially on the substrate surface and subsequently on the deposited material's surface, 


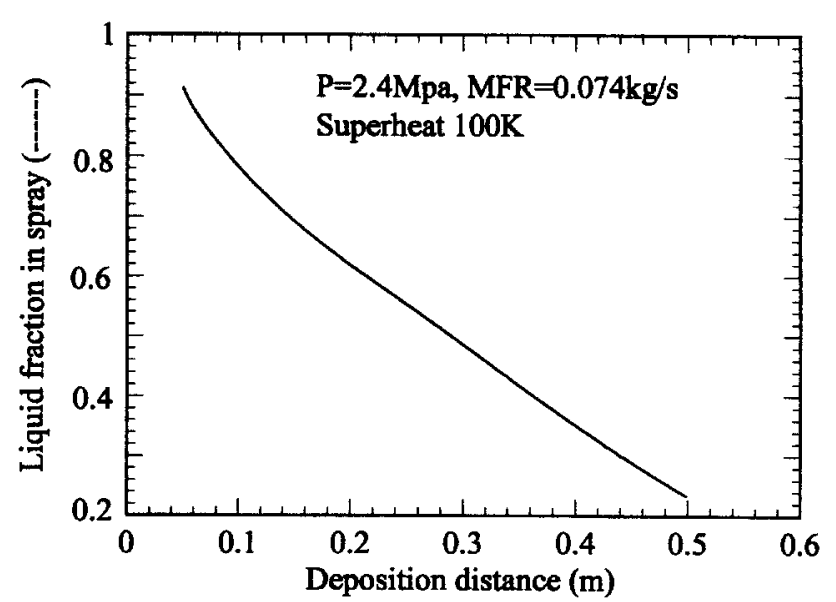

Fig. 4-Liquid fraction in spray during spray forming of tool steel A2.

can be approximated by a finite sequence of droplet depositions, with a small time interval between impacts of successive groups of droplets. ${ }^{[8,20]}$ The solidification process on the top of the deposit can be described in the following sequence. At the initial stage, the droplets impinge onto the cold surface and complete solidification occurs before the next group of droplets arrives. During this stage, droplets are deposited on a solid surface $\left(f_{l, d}=0\right)$. With a thickening of the deposit, the temperature on the deposit surface increases due to the increase of internal conduction resistance. At a certain thickness, the temperature exceeds the solidus temperature, and a liquid phase appears in the deposit's surface. A mushy layer also starts to form. ${ }^{[20]}$ In this article, the region prior to the mushy layer is termed the chill zone. Subsequently, the temperature and the fraction of liquid on the deposit's surface continue to increase and ultimately approach those of the incoming droplets.

It is well known that in the chill zone, there exists high porosity, which leads to poor mechanical properties. The high porosity in this region is attributable to incomplete droplet spreading and the large concentration of a priordroplet boundary. ${ }^{[21]}$ Thus, suitable processing parameters must be selected to reduce the thickness of the chill zone or to eliminate it, especially in the case of target preforms with the small total thickness (i.e., plates). Reference 21 reveals that the interfacial heat-transfer coefficient significantly affects the formation of the mushy layer. In the case of a very low heat-transfer coefficient between the substrate and deposition (e.g., $1.0 \cdot 10^{3} \mathrm{~W} \cdot \mathrm{m}^{-2} \cdot \mathrm{K}^{-1}$ corresponding to the ceramic substrate $\left.{ }^{[1]}\right)$, the chill zone is very thin and sometimes even disappears. Hence, in this article, a ceramic substrate is selected, in order to obtain plates with an ideal microstructure on their bottom region. Hence, it can be assumed that in our experiments, the liquid fraction on the top surface of the plates is equal to that in the spray during spray forming. The value of $S E_{t}$ is given from the following equation: ${ }^{[8]}$

$$
S E_{t}=0.25+1.48 f_{l, s}-0.75 f_{l, s}^{2}
$$

\section{Evolution of Plate Surface}

At any point $P$, the growth $(\Delta h)$ from $t$ to $t+\Delta t$ is given by the following equation:

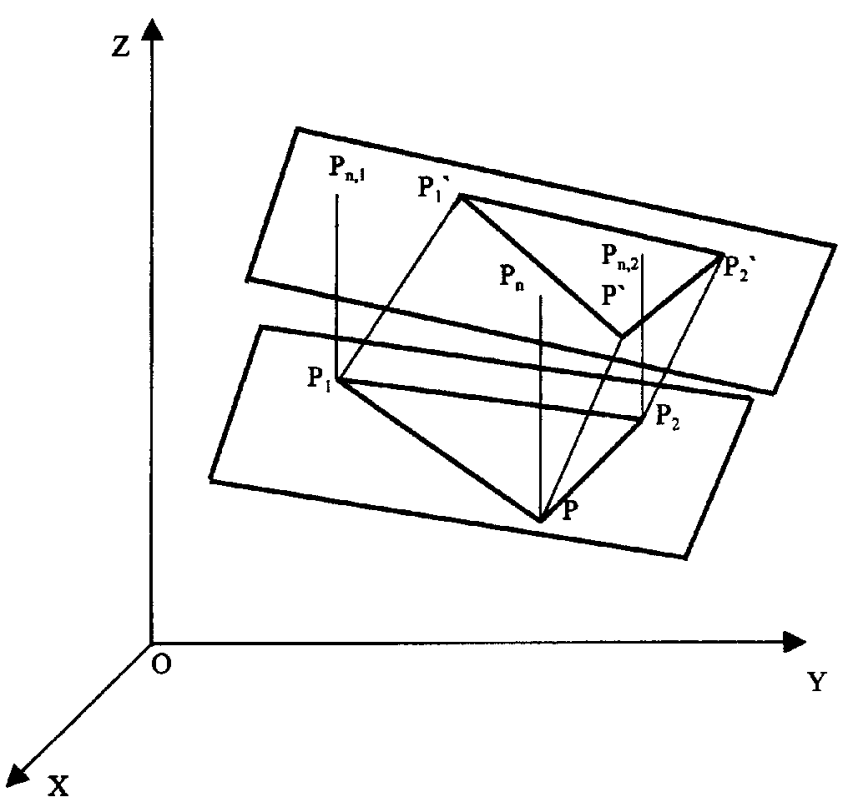

Fig. 5-Schematic diagram of surface evolution using the three-point model.

$$
\Delta h=\int_{t}^{t+\Delta t}\left|\frac{\mathbf{e}_{n} \cdot \mathbf{e}_{f}}{\mathbf{e}_{s} \cdot \mathbf{e}_{f}}\right| \cdot S E \cdot \xi \cdot a \exp \left(-b s^{2}\right) \mathbf{d} t
$$

The new points, $P^{\prime}$, are obtained from the following equation:

$$
P^{\prime}=P+\Delta h \cdot \mathbf{e}_{n}
$$

At the time $t+\Delta t$, the new positions of all points in the surface define the new geometry of the plate surface. However, after a certain amount of computing steps, the relative position between the three points $P, P_{1}$, and $P_{2}$ changes, such that the distance between the three points become sufficiently large, bringing about unacceptable error when Eq. [6] is used to calculated the unit-normal vector of the plate surface at the point $P$. In order to solve this problem, a method called "point interpolation" is used, as shown in Figure 5.

First, the three new points, $P^{\prime}, P_{1}{ }^{\prime}$, and $P_{2}{ }^{\prime}$, corresponding to $P, P_{1}$, and $P_{2}$, respectively, obtained from Eq. [21], constitute a plane with unit-normal vector of $\mathbf{e}_{n}{ }^{\prime}$. Due to the very small distance between the three points, the surface that intersects them approximates the plane. Then, three straight lines passing through $P, P_{1}$, and $P_{2}$ and parallel to the $Z$ axis are made and intersect with the plane at $P_{n}, P_{n, 1}$, and $P_{n, 2}$. These points will also approximate the plate's surface, as long as the component along the $Z$-axis of $\mathbf{e}_{n}$ is large enough. In this study, $\mathbf{e}_{n, z} \geq \sqrt{3} / 3$, meaning that the direction angle of $\mathbf{e}_{n}$ with the $Z$-axis must be less than $54.7 \mathrm{deg}$. Finally, $P_{n}, P_{n, 1}$, and $P_{n, 2}$ are the three new points for computation in the next step, at $t+2 \Delta t$. Physically, the objective of this approach is to establish the increase in thickness at the three points $P, P_{1}$, and $P_{2}$.

The coordinates of $P_{n}, P_{n, 1}$, and $P_{n, 2}$ can be calculated from the following equation:

$$
\left\{\begin{array}{l}
x_{n}=x \\
y_{n}=y \\
z_{n}=\frac{\mathbf{e}_{n x}^{\prime}\left(x_{p}^{\prime}-x\right)+\mathbf{e}_{n y}^{\prime}\left(y_{p}^{\prime}-y\right)}{\mathbf{e}_{n z}^{\prime}}+z_{p}^{\prime}
\end{array}\left(\mathbf{e}_{n, z} \geq \sqrt{3 / 3}\right)\right.
$$


Where $\left(x_{n}, y_{n}, z_{n}\right)$ represent the coordinates of any one of the points $P_{n}, P_{n, 1}$ and $P_{n, 2},(x, y, z)$ represent the coordinates of any one of the points $P, P_{1}$ and $P_{2} ;\left(x_{p}^{\prime}, y_{p}^{\prime}, z_{p}^{\prime}\right)$ represent the coordinates of the point $P^{\prime} ; e_{n x}^{\prime}, e_{n y}^{\prime}$ and $e_{n z}^{\prime}$ represent $\mathrm{x}$, $\mathrm{y}$ and $\mathrm{z}$ components of $\mathbf{e}_{n}^{\prime}$. The points $P_{n}, P_{n, 1}$ and $P_{n, 2}$ are taken as the points in the new surface for the next calculation.

Beginning with a flat substrate, the value of $\mathbf{e}_{n, z}$ is much larger than $\mathbf{e}_{n, x}$ and $\mathbf{e}_{n, y}$. The component $\mathbf{e}_{n, z}$ decreases gradually with spray forming, especially on the side area of the plate. As shown in Figure 5, a low $\mathbf{e}_{n, z}$ leads to $P_{n}, P_{n, 1}$ and $P_{n, 2}$, far away from triangle, and the plate's surface near $P_{n}$, $P_{n, 1}$ and $P_{n, 2}$ will not be approximated by the plane passing through $P^{\prime}, P_{1}{ }^{\prime}$ and $P_{2}{ }^{\prime}$. In this case, either $\mathbf{e}_{n, x}$ or $\mathbf{e}_{n, y}$ becomes larger than any of the other two components. One then makes straight lines parallel to the $X$ - (if $\mathbf{e}_{n, x}$ is the largest) or $Y$ - (if $\mathbf{e}_{n, y}$ is the largest) axes to find the three points for the next step calculation of the surface evolution. Similar equations (such as Eq. [23]) are used to calculate the coordinates of $P_{n}, P_{n, 1}$ and $P_{n, 2}$. The previous algorithm can be described as follows:

Initialize coordinates of all points on the substrate surface for ( $t$ from 0 to total process time, step $d t$ )

for ( $Y$ coordinate from 0 to $Y_{\max }$, step $d y$ )

for $\left(X\right.$ coordinate from 0 to $X_{\max }$, step $d x$ )

calculate unit normal vector $\mathbf{e}_{n}$ of the plane defined by $P, P_{1}$, and $P_{2}$, using Eq. [6]

calculate growth points of $\mathrm{P}^{\prime}, \mathrm{P}_{1}^{\prime}$ and $\mathrm{P}_{2}^{\prime}$ from $P, P_{1}$, and $P_{2}$, using Eq. [22]

calculate unit normal vector $\mathbf{e}_{n}{ }^{\prime}$ of the plane defined by $\mathrm{P}^{\prime}, \mathrm{P}_{1}{ }^{\prime}$ and $\mathrm{P}_{2}{ }^{\prime}$, using Eq. [6]

if $\left(\mathbf{e}_{n, z}\right.$ is not less than $\left.1 / \sqrt{3}\right)\{$

calculate the $Z$-coordinate values of points $P_{n}, P_{n, 1}$, and $P_{n, 2}$, using Eq. [23]

(keep $X$ - and $Y$-coordinate values unchanged)

\}

else if $\left(\mathbf{e}_{n, y}\right.$ is not less than $\left.1 / \sqrt{3}\right)$ \{

calculate the $Y$-coordinate values of points $P_{n}, P_{n, 1}$, and $P_{n, 2}$, using Eq. [23]

(keep $X$ - and $Z$-coordinate values unchanged)

\}

else \{

calculate the $X$-coordinate values of points $P, P_{n, 1}$, and $P_{n, 2}$, using Eq. [23]

(keep $Y$ - and $Z$-coordinate values unchanged)

\}

end for

end for

end for

\section{COMPUTATIONAL RESULTS}

\section{A. Influence of Acceleration in the Reciprocal Movement Direction (X-Axis)}

Figures 6(a) through (d) show the three-dimensional geometry of plates spray formed with a stroke time of 1 second in the $X$-axis, a movement velocity of $2 \mathrm{~mm} / \mathrm{s}$ in the $Y$-axis, and accelerations of $1,2,5$, and $10 \mathrm{~m} \cdot \mathrm{s}^{-2}$, respectively. It can be seen from the three-dimensional graphs, shown in Figures 7(a) through (d) at $5 \mathrm{~mm}$ intervals, that the maximum range in which the cross sections parallel to the $X$-axis are identical to each other is $Y \approx 30$ to $130 \mathrm{~mm}$. It is demonstrated in Figures 7(a) through (d) that a decrease

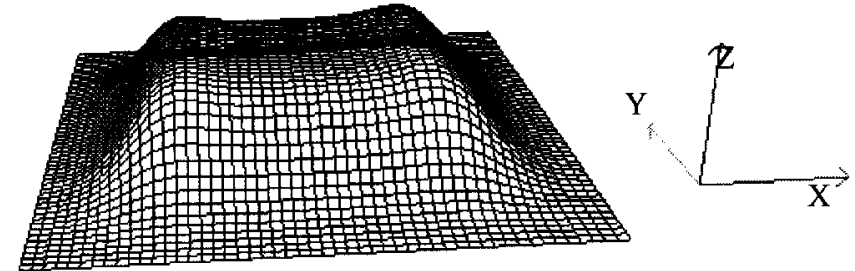

(a)
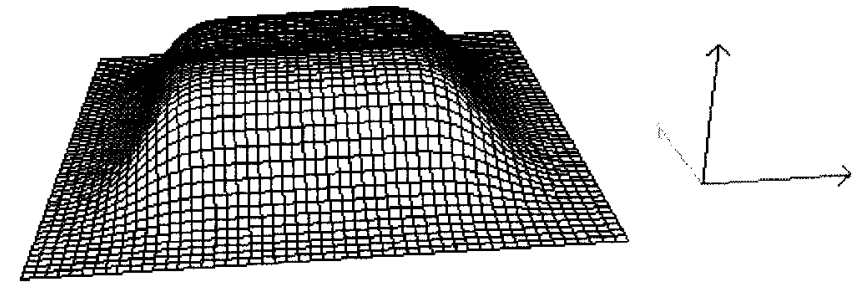

(b)
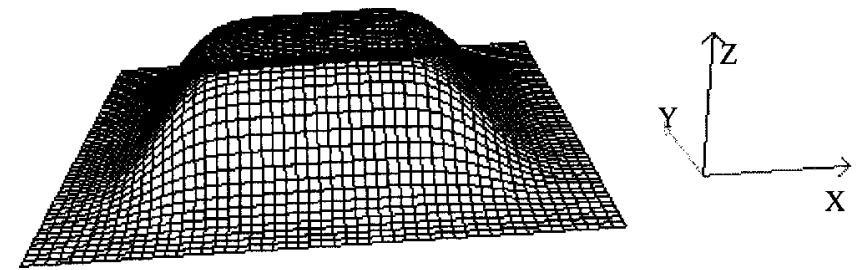

(c)
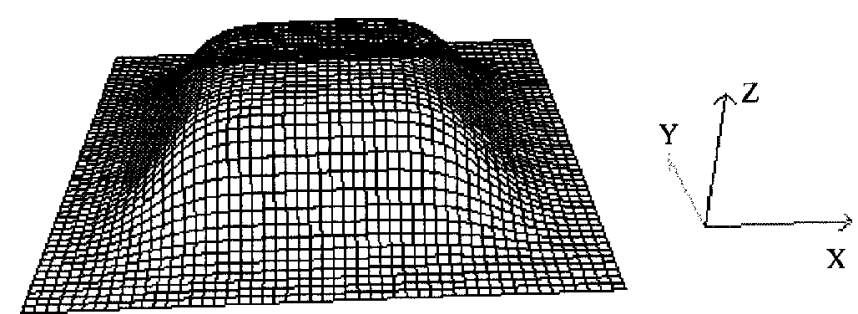

(d)

Fig. 6-Three-dimensional geometry of plates spray formed with the time for a stroke of $1 \mathrm{~s}$ and movement velocity of $2 \mathrm{~mm} / \mathrm{s}$ in the $Y$-axis and at various accelerations in the $X$-axis: (a) $1 \mathrm{~m} \cdot \mathrm{s}^{-2}$, (b) $2 \mathrm{~m} \cdot \mathrm{s}^{-2}$, (c) $5 \mathrm{~m}$. $\mathrm{s}^{-2}$, and $(d) 10 \mathrm{~m} \cdot \mathrm{s}^{-2}$.

in acceleration in the $X$-axis leads to an increase in thickness in the side regions and a decrease in thickness in the uniformthickness regions. However, the effect of the acceleration along the $X$-axis on the height of the side and middle regions of a plate varies from low accelerations to high ones. On one hand, with low values of acceleration, the change of height of the side and middle regions is sensitive to the change of acceleration. For example, the range of the uniform-thickness region decreases from 20 to $130 \mathrm{~mm}$ to 25 to $125 \mathrm{~mm}$ when $A$ changes from $2 \mathrm{~m} \cdot \mathrm{s}^{-2}$ (Figure 7(b)) to $5 \mathrm{~m} \cdot \mathrm{s}^{-2}$ (Figure 7(c)). Even $A=1 \mathrm{~m} \cdot \mathrm{s}^{-2}$ (Figure 7(a)) leads to heights in some positions in the plate's side higher than that of the uniform-thickness region. On the other hand, the geometries of the plates with $A=5$ and $10 \mathrm{~m} \cdot \mathrm{s}^{-2}$ are almost the same, implying that the acceleration in the $X$ axis hardly affects the final geometry of the plates.

The different percentages of acceleration and deceleration times taken in the stroke time are responsible for the previous results. In the case of small accelerations in the $X$-axis (e.g., $A<2 \mathrm{~m} \cdot \mathrm{s}^{-2}$ ), the acceleration time required for a stroke 


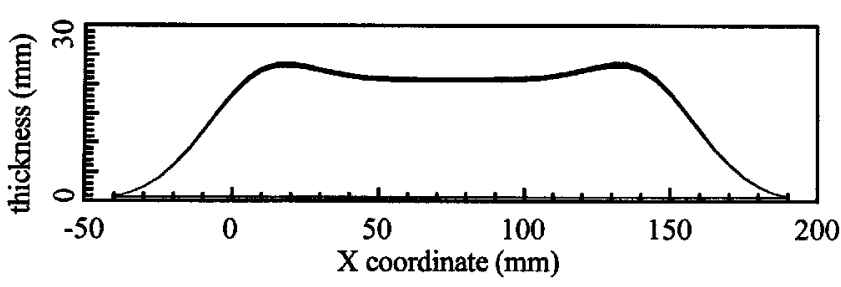

(a)

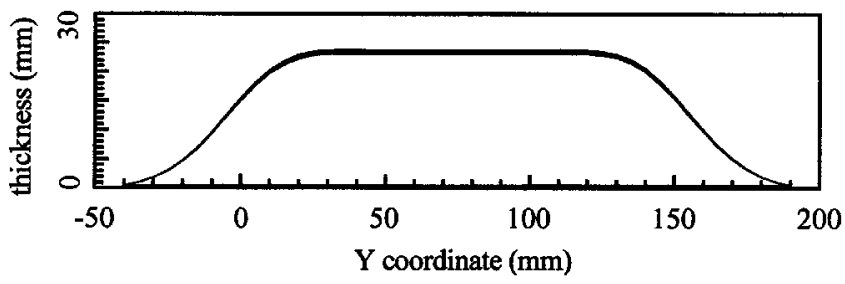

(b)

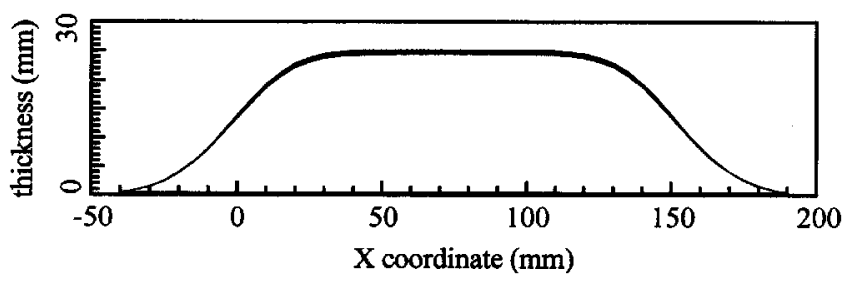

(c)

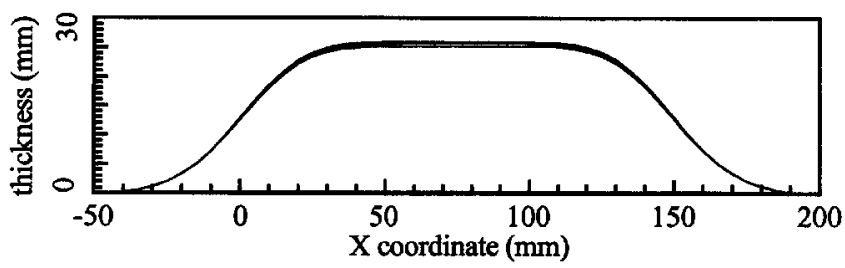

(d)

Fig. 7-Cross sections of plates parallel to the $X$-axis at 5-mm intervals in the range of $Y=35$ to $125 \mathrm{~mm}$. The plates are spray formed with the time for a stroke of $1 \mathrm{~s}$ and movement velocity of $2 \mathrm{~mm} / \mathrm{s}$ in the Y-axis and at various accelerations in the $X$-axis: (a) $1 \mathrm{~m} \cdot \mathrm{s}^{-2}$, (b) $2 \mathrm{~m} \cdot \mathrm{s}^{-2},(c)$ $5 \mathrm{~m} \cdot \mathrm{s}^{-2}$, and $(d) 10 \mathrm{~m} \cdot \mathrm{s}^{-2}$.

is very sensitive to $A$. For example, the percentage of $t a$ is approximately 18 and 8 pct for $A=1$ and $2 \mathrm{~m} \cdot \mathrm{s}^{-2}$, respectively. As a result, the different final geometry arises. In the case of a large acceleration, the percentage is 3 and 1.5 pct for $A=5$ and $10 \mathrm{~m} \cdot \mathrm{s}^{-2}$, respectively. Thus, the final geometry under the two accelerations is almost the same, and the influence of $A$ is negligible.

\section{B. Influence of the Stroke Time}

Figures 8(a) through (d) show the three-dimensional geometries of plates spray formed with an acceleration of $2 \mathrm{~m} \cdot \mathrm{s}^{-2}$, a movement velocity of $2 \mathrm{~mm} / \mathrm{s}$ in the $Y$-axis, and stroke times of $1,4,8$, and 20 seconds, respectively. It is shown from these three-dimensional graphs that the maximum ranges in which the cross sections parallel to the $X$-axis are identical to each other are approximately $Y=30$ to $130 \mathrm{~mm}$ for $T=1,4$, and 8 seconds, which are shown in Figures 8(a) through (c), respectively. To $T=20$ seconds, the region with a uniform thickness cannot be spray formed (Figure 8(d)).

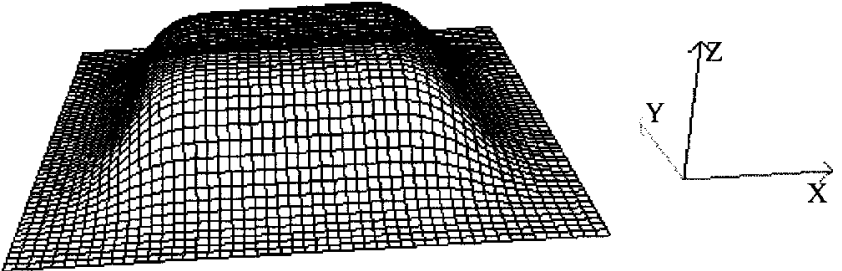

(a)

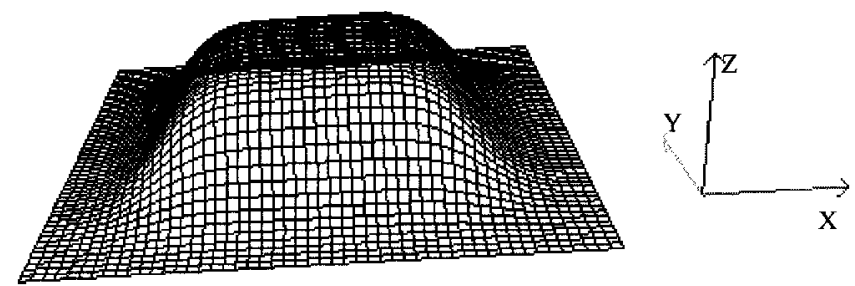

(b)
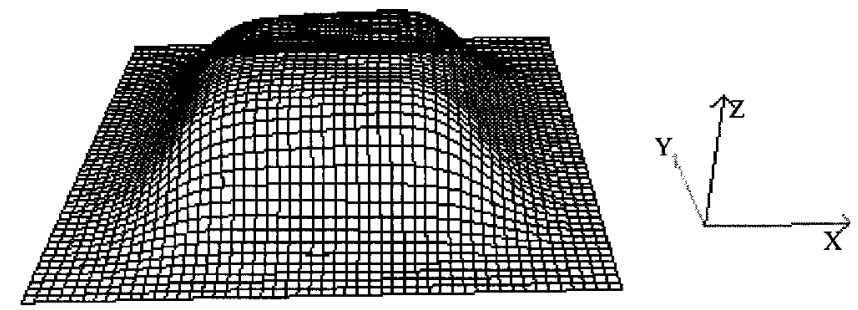

(c)

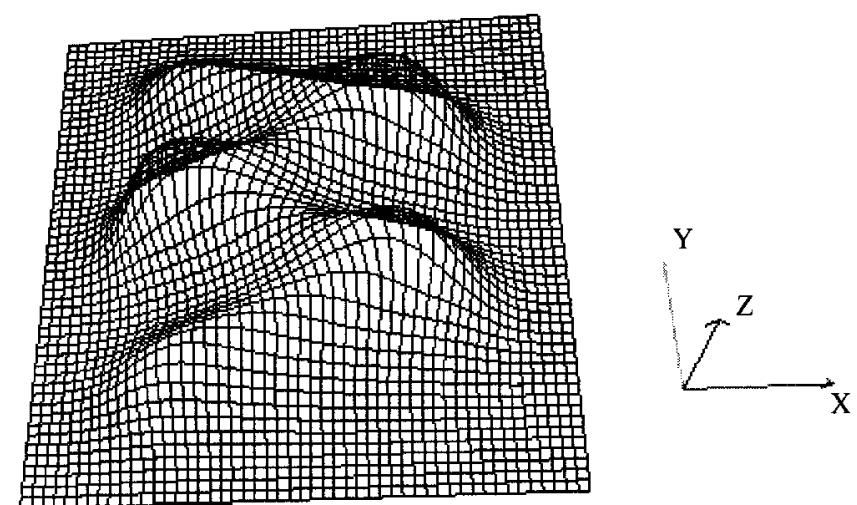

(d)

Fig. 8-Three-dimensional geometry of plates spray formed with acceleration of $2 \mathrm{~m} \cdot \mathrm{s}^{-2}$ in the $X$-axis, movement velocity of $2 \mathrm{~mm} / \mathrm{s}$ in the $Y$ axis, and at various stroke times: (a) $1 \mathrm{~s}$, (b) $4 \mathrm{~s},(c) 8 \mathrm{~s}$, and (d) $20 \mathrm{~s}$.

Comparing the cross sections shown in Figures 9(a) through (c), it is shown that the cross sections at Figures 9(b) and (c) almost coincide, whereas the cross section in Figure 9(a) possesses a shorter transition region and lower thickness. The reason why the geometry of the plate with $T=1$ second is the different from those with $T=4$ and 8 seconds is different percentage of time the acceleration takes, as described in the preceding paragraph.

\section{Influence of Velocity in the Uniform-Velocity Movement Direction (Y-Axis Direction)}

With a fixed travel distance of the track of the spray axis in the $Y$-axis, the change of velocity along the $Y$-axis will lead to different spray times. In this article, $a_{s} / V$ is kept 


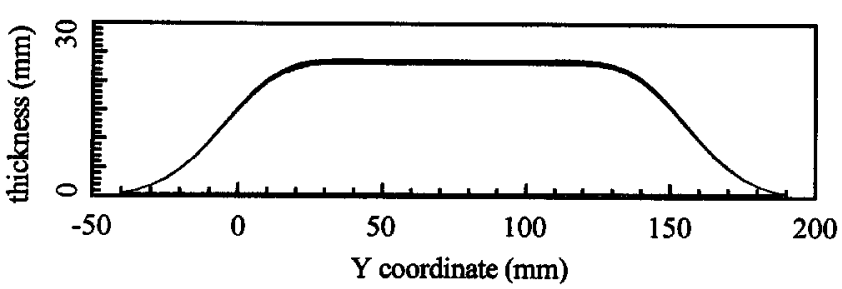

(a)

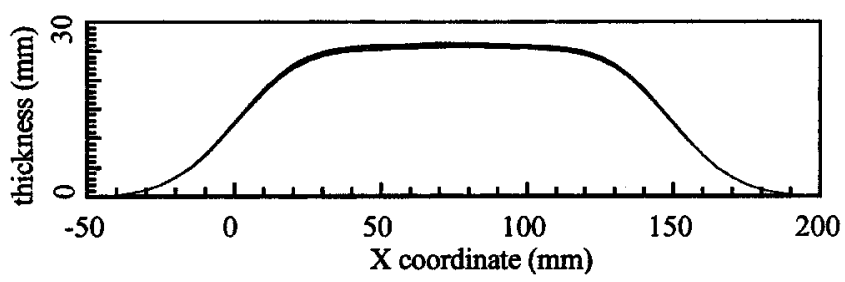

(b)

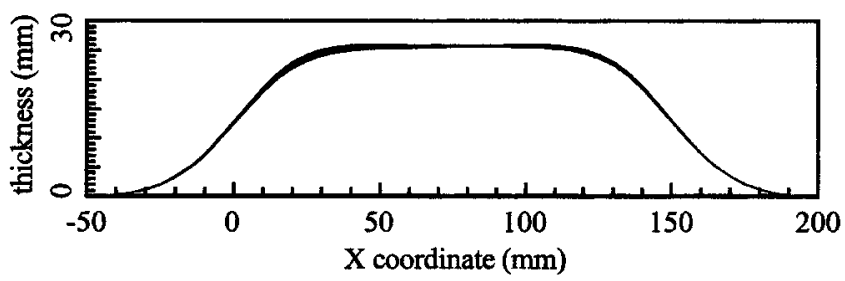

(c)

Fig. 9-Cross sections of plates parallel to the $X$-axis at 5-mm intervals in the range of $Y=30$ to $130 \mathrm{~mm}$. The plates are spray formed $2 \mathrm{~m} \cdot \mathrm{s}^{-2}$ in the $X$-axis, movement velocity of $2 \mathrm{~mm} / \mathrm{s}$ in the $Y$-axis, and at various stroke times: (a) $1 \mathrm{~s},(b) 4 \mathrm{~s}$, and (c) $8 \mathrm{~s}$.

constant for the same total atomized mass. Figures 10(a) through (c) show three-dimensional geometries of plates spray formed with an acceleration of $2 \mathrm{~m} \cdot \mathrm{s}^{-2}$, a stroke time of 20 seconds, and movement velocities of $0.5,1$, and $2 \mathrm{~mm} / \mathrm{s}$ along the $Y$-axis, respectively. With $V=0.5$ and $1 \mathrm{~mm} / \mathrm{s}$, the plate's final geometries are almost the same. However, with $V=2 \mathrm{~mm} / \mathrm{s}$, a plate with uniform-thickness region cannot be produced.

\section{DISCUSSION}

\section{A. Evaluations of Processing Parameters}

Spray forming, a near-net-shape technique, aims to create products with a desired geometry, fine microstructure, high density, as well as high deposition yield. Microstructure and porosity in spray-formed materials are the two subjects of many numerical and experimental research efforts, in which the influences of various parameters of spray atomization and substrate motion on these two aspects have been systematically investigated. However, the evaluation of the final spray-formed geometry and its corresponding processing parameters have been paid little attention. On the basis of the computational results using the mathematical model, the authors will attempt to propose a methodology to evaluate the final geometry and the corresponding processing parameters.

In the case of spray-formed plates, uniform heights are desired. In the following discussion, deposits in the range across which the track of the spray axis sweeps, i.e., 150

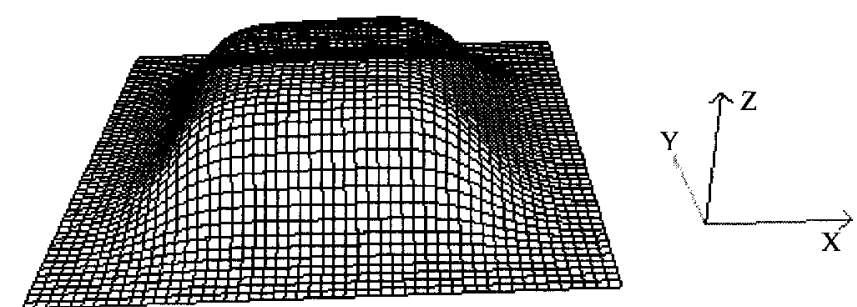

(a)

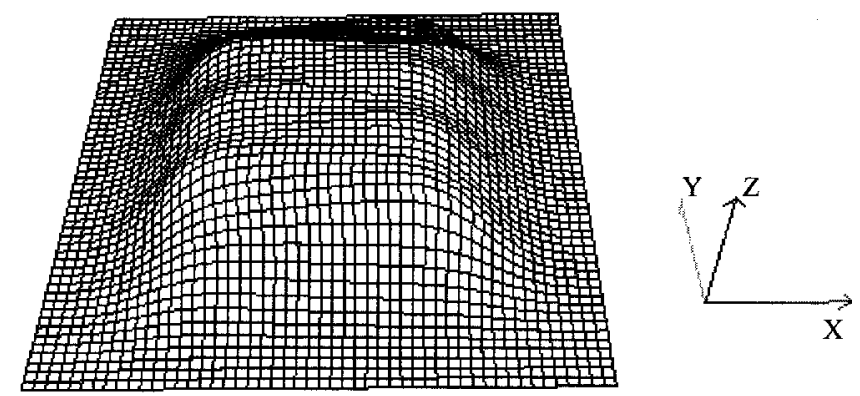

(b)

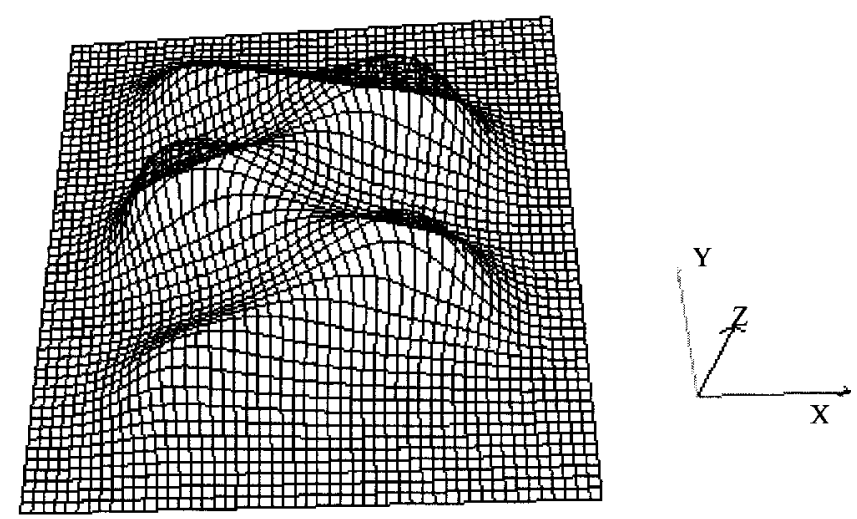

(c)

Fig. 10-Three-dimensional geometry of plates spray formed with acceleration of $2 \mathrm{~m} \cdot \mathrm{s}^{-2}$ in the $X$-axis, stroke time of $20 \mathrm{~s}$, at various movement velocities of $2 \mathrm{~mm} / \mathrm{s}$ in the $Y$-axis: (a) $0.5 \mathrm{~mm} / \mathrm{s},(b) 1 \mathrm{~mm} / \mathrm{s}$, and (c) 2 $\mathrm{mm} / \mathrm{s}$.

$\mathrm{mm}$ (in the $X$-axis) $\times 160 \mathrm{~mm}$ (in the $Y$-axis), are taken as final products.

The mean-squared surface roughness $(M S)$ is introduced to evaluate the uniformity of the surface height. It can be calculated from the following equation:

$$
M S(T, A, V)=\frac{\sum_{n=1}^{N}\left(h_{n}-\bar{h}\right)^{2}}{N}
$$

Where $N$ is the total amount of investigated points, $h_{n}$ is the height at point $n$, and $\bar{h}$ is the average height of the $N$ points. The smaller the value of $M S$, the more uniform the plates.

Our goal is to minimize the mean-squared surface roughness $M S(T, A, V)$, which is related to the stroke time, $T$; the acceleration along the $X$-axis, $A$; and the velocity along the $Y$-axis, $V$. Varying $T, A$, and $V$, the minimum value $\left(M S_{\text {min }}\right)$ can be found for certain parameters. The following algorithm is used in this article to compute the minimum mean-squared surface roughness: 


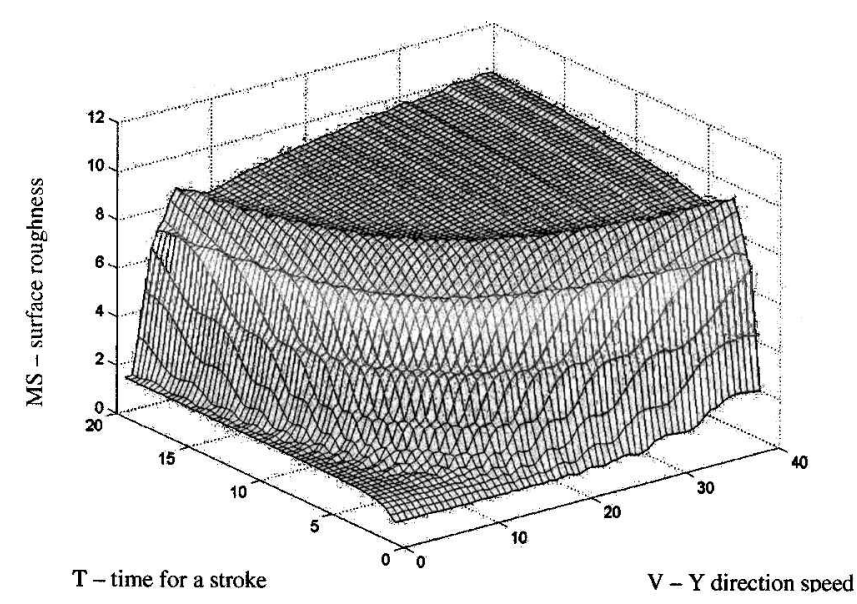

Fig. 11-Surface roughness as a function of the velocity along the $Y$-axis at various stroke times. $A=1\left(\mathrm{~m} \cdot \mathrm{s}^{-2}\right), T=0.6$ to $20 \mathrm{~s}$, and $V=0.5$ to $40 \mathrm{~mm} / \mathrm{s}$.

Loop:

Vary $V$, the velocity along $Y$-axis direction \{ Vary $A$, the acceleration along $X$-axis direction \{ Vary $T$, the time for a stroke \{ $M S=M S(T, A, V)$ Eq. [24]

If $M S \leq M S_{\min }\{$

Save $M S=M S_{\min }$

Save $V, A, T$

\}

\}

\}

\}

Figure 11 shows the $M S$ surface roughness as a function of velocity along the $Y$-axis, at different stroke times. In Figure 11 , the acceleration along the $X$-axis, and the total atomized material volume during spray forming are kept constant. For a given stroke time, the $M S$ surface roughness is almost constant below a critical velocity along the $Y$ axis. However, above the critical velocity, the $M S$ surface roughness increases rapidly. A similar trend for the change in $M S$ surface roughness is observed for different stroke times, although the critical velocity along the $Y$-axis decreases with increasing stroke times. Comparing the results at $T=20$ seconds with the plate geometries in Figures through 10 (a) through (c), it is shown that the dramatic increase of $M S$ surface roughness results from the fact that only very low values for $V$ will create uniform heights. It also implies that below the critical velocity, the height fluctuation is so small that it hardly affects the $M S$ surface roughness.

Figure 13 shows the $M S$ surface roughness as a function of acceleration along the $X$-axis, for different velocities along the $Y$-axis. The $M S$ surface roughness increases as the velocity along the $Y$-axis increases, especially when $V$ reaches a certain value $(\approx 30 \mathrm{~mm} / \mathrm{s})$, at which point $M S$ increases dramatically, and the acceleration along the $X$-axis, doesn't affect this value. Hence, the critical value of velocity is only a function of the stroke time. The critical value of velocity as a function of the stroke time, is plotted in Figure 12. It is interesting that the curve is a hyperbola with the expression $V T=$ constant. For a given velocity, as $A$ increases from 0 , $M S$ first decreases dramatically. When $A \approx 600 \mathrm{~mm} \cdot \mathrm{s}^{-2}$,

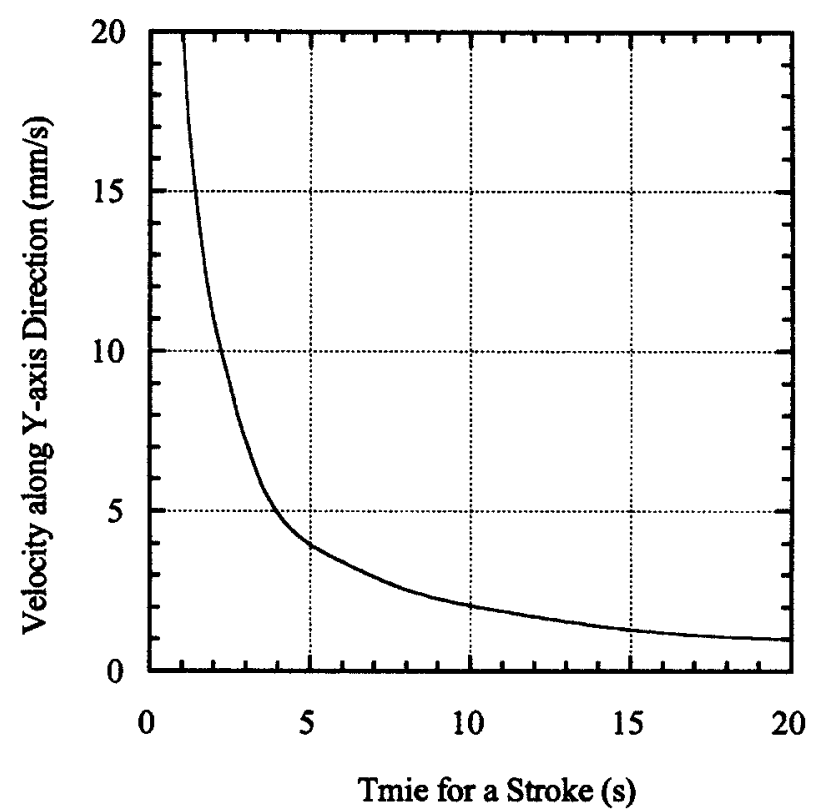

Fig. 12-The critical velocity along the $Y$-axis as a function of the stroke time.

$M S$ reaches its minimum value. When $A$ increases beyond $600 \mathrm{~mm} \cdot \mathrm{s}^{-2}$ (Figure 13(b)), MS increases and approaches a constant value.

Figures 6 through 8 and 10 show that the deposition on the side areas of the substrate has the most effect on the $M S$ surface-roughness value. When the nozzle reverses its direction of travel, the spray hits on the very edge area (at $x=0$ or at $x=S$ ) twice in a very short time. After $2 T$ seconds, the spray hits on the same edge area again, but the intersection of the spray axis with the substrate has moved by a distance of $2 V T$ along the $Y$-axis from the previous one. Hence, the smaller the value of $2 V T$, the more uniform the deposited mass distribution in the side areas, and the more uniform the overall deposition mass distribution. The value of $V T$ is thought to be the criterion to evaluate height uniformity along the $Y$-axis. With the value of $V T$ below a critical one, the height fluctuation is so small that it hardly affects the $M S$ surface roughness. Above the critical value of $V T$, the $M S$ surface roughness increases rapidly, due to the large change of heights caused by the geometry without a uniform height region.

Figure 14 shows the $M S$ surface roughness as a function of acceleration along the $X$-axis, at different stroke times. The $M S$ surface roughness decreases with decreasing acceleration until the minimum value. Then, the $M S$ surface roughness increases sharply with a decrease of acceleration. This tendency is consistent with the change of the plate's morphology. As shown in Figures 7(a) through (d), the decrease of acceleration results in the increase of height in the plate's side. However, too-low an acceleration alone leads to an excessive increase of height in the plate's sides and decrease of height in the middle region of the plate. As a consequence, the $M S$ surface roughness increases. The acceleration corresponding to the minimum $M S$ surface roughness also decreases with increasing stroke time. In Figure 14, the minimum $M S$ surface roughness is a relatively flat function of the acceleration and the stroke time. The overall $M S$ value increases as the stroke time increases, and 


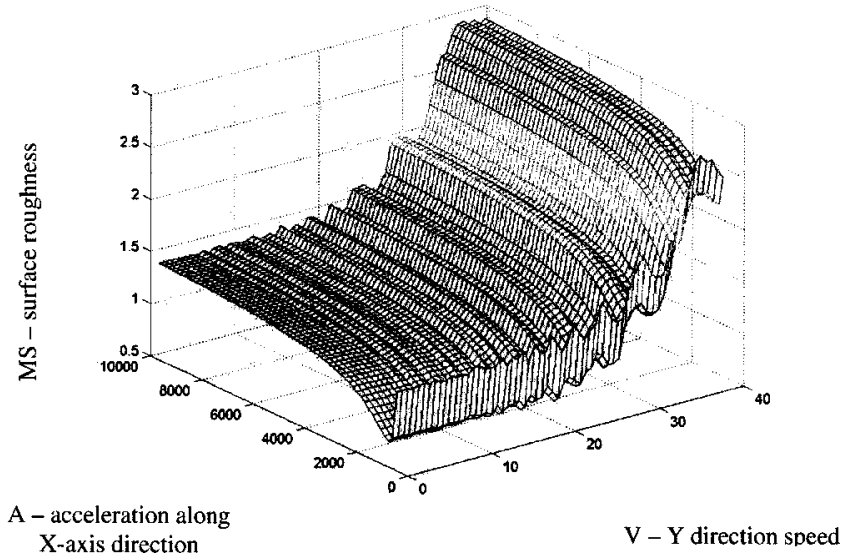

(a)

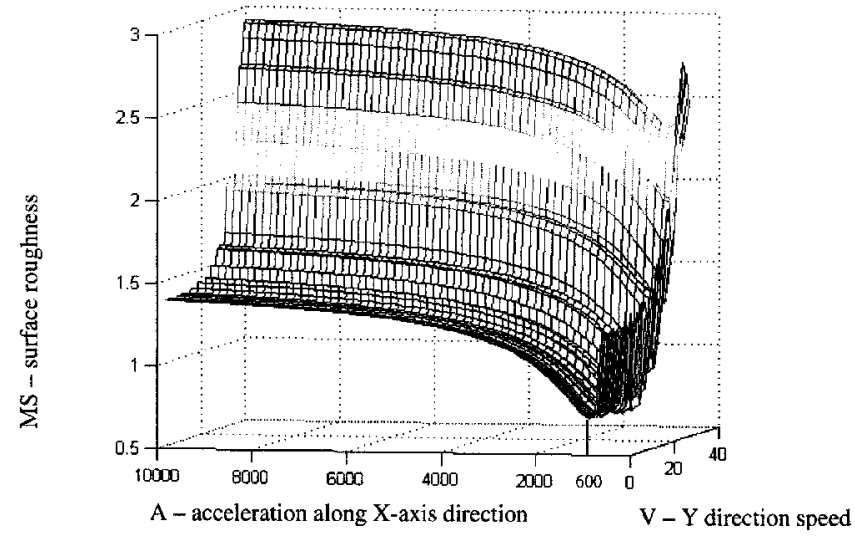

(b)

Fig. 13-Surface roughness as a function of velocity along the $Y$-axis at various accelerations along the $X$-axis. $T=1 \mathrm{~s}, A=0.6$ to $10\left(\mathrm{~m} \cdot \mathrm{s}^{-2}\right)$, and $V=0.5$ to $40 \mathrm{~mm} / \mathrm{s}$. (a) and $(b)$ are from different points of view.

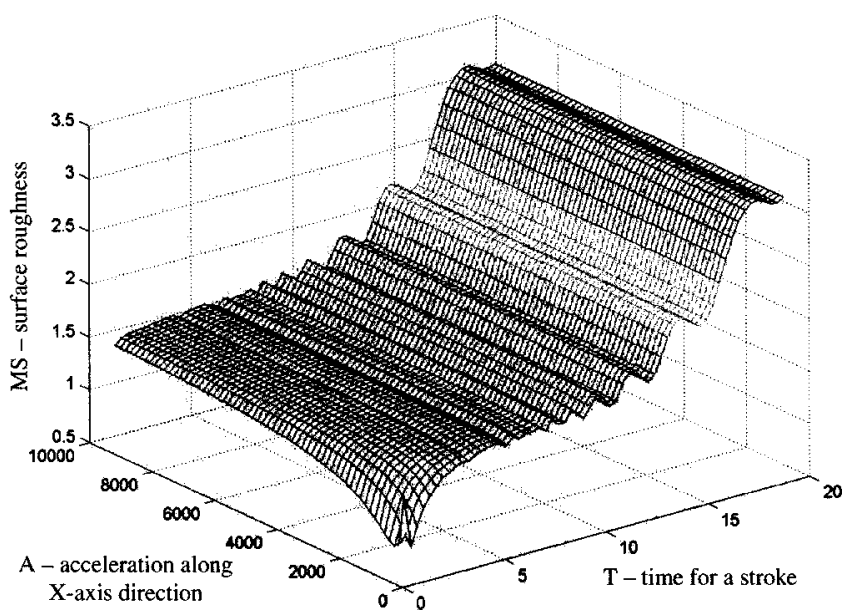

Fig. 14-Surface roughness as a function of acceleration along the $X$-axis at various stroke times. $V=2 \mathrm{~m} \cdot \mathrm{s}^{-2}, A=0.6$ to $10 \mathrm{~m} \cdot \mathrm{s}^{-2}, T=0.6$ to $20 \mathrm{~s}$.

it increases dramatically when $T$ reaches a certain value. Figure 14 also shows that at a certain velocity along the $Y$ axis, the $M S$ surface-roughness value varies the most with a variation of the stroke time, while the acceleration along the $X$-axis does not have a large effect on the $M S$ value.

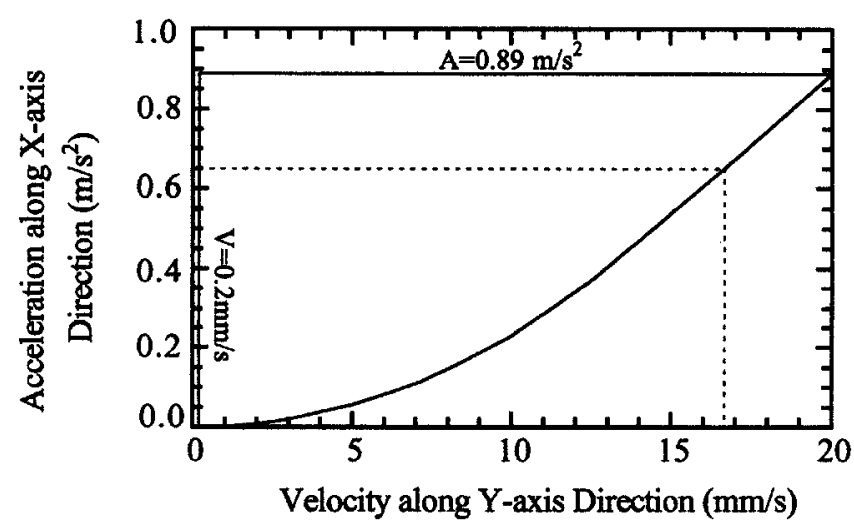

(a)

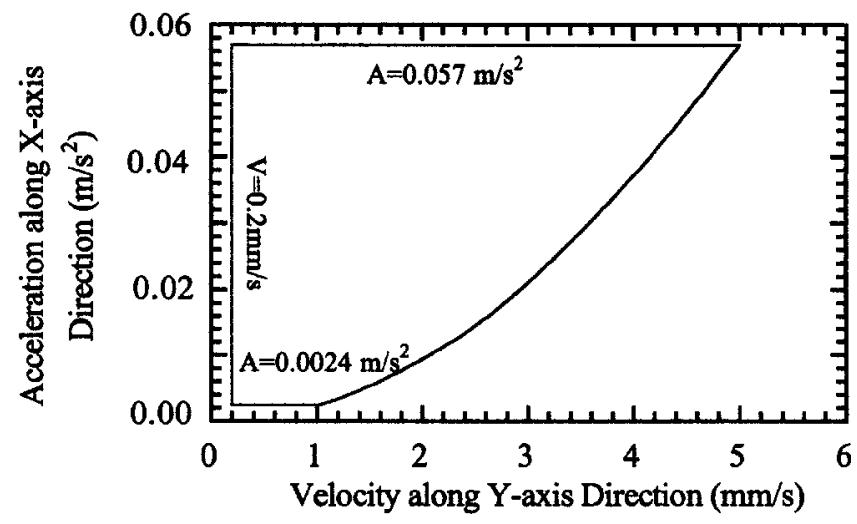

(b)

Fig. 15-(a) The map of the optimal combinations of processing parameters and $(b)$ an enlarged portion of (a).

\section{B. Optimal Combinations of Processing Parameters}

Because only the $M S$ surface roughness is considered in this article, the exploration of the optimal combinations of processing parameters is based on this aspect.

On the basis of the calculated results described in Figures 11,13 , and 14 , the optimal combinations of processing parameters corresponding to the minimum $M S$ surface roughness can be readily obtained. First, the range of velocities along the $Y$-axis for the optimal combinations of processing parameters is determined, for example, $T=1 \mathrm{~s}$. As shown in Figure 12, the critical velocity along the $Y$-axis is approximately $20 \mathrm{~mm} / \mathrm{s}$. According to the results shown in Figure 14, the critical velocity is independent of the acceleration along the $X$-axis. Thus, for any value of acceleration, the range of velocities along the $Y$-axis for the optimal combinations of processing parameters is below $20 \mathrm{~mm} / \mathrm{s}$. Second, for any velocity along the $Y$-axis below the critical value, the acceleration corresponding to the minimum $M S$ surface roughness can be found. The curve in Figure 15 shows the optimal accelerations along the $X$-axis as a function of the critical velocities along the $Y$-axis (i.e., for $T=1 \mathrm{~s}, A_{\text {optimal }}$ $=0.89 \mathrm{~m} / \mathrm{s}^{2}$ ) in the range of $T=1-20 \mathrm{~s}$ (the range of the critical velocities along $Y$-axis direction $V=1-20 \mathrm{~mm} / \mathrm{s}$ ). Due to the fact that the $M S$ surface roughness is nearly constant below the critical velocity, there are many optimal combinations of processing parameters. (See Page 9). Considering that too small a velocity along the $Y$-axis and, therefore, too small a metal flow rate (in order to maintain the 
same total atomized mass) reduces production efficiency, $0.2 \mathrm{~mm} / \mathrm{s}$ is arbitrarily taken as the minimum velocity along the $Y$-axis. In Figure 15(a), the data points falling into the region surrounded by $A=0.89 \mathrm{~m} / \mathrm{s}^{2}, V=0.2 \mathrm{~mm} / \mathrm{s}$, and the curve give optimal combinations of processing parameters to achieve the minimum $M S$ surface roughness. Figure 15(b) is an enlarged portion of low acceleration, in order to show the portion clearly. The two figures are maps for the optimal combinations of processing parameters. By combining the map with Figure 12, the optimal values can be conveniently found. For example, for a time of $T=1.2 \mathrm{~s}$, from Figure 12 , the optimal range of velocities along the $Y$-axis is $V \leq$ $16.7 \mathrm{~mm} / \mathrm{s}$; from Figure 15(a), the optimal acceleration along the $X$-axis is $0.65 \mathrm{~m} / \mathrm{s}^{2}$.

It is worth noting that the applicable range of stroke times is determined by two factors. First, during spray forming, deposition in some positions of the plate's surface is suspended if the distance is too far from the atomizer spray axis. Long stroke times make the surface temperature drop so much that when deposition starts again, the incoming droplets cannot remelt the solidified surface and nonatomic bonding may occur between the deposited surface and newly deposited material. ${ }^{[21]}$ Second, too-short a stroke time leads to severe vibration and shock.

\section{CONCLUSIONS}

1. A mathematical model to couple thermal and geometric factors has been established. Using the model, the final geometry of the plates is calculated using a fixed atomizer along the $Z$-axis and a substrate moving along the $X$-axis and $Y$-axis.

2. The value of the products of the velocities along the $Y$-axis and the stroke times is the criterion for height uniformity in the middle regions of plates, regardless of the acceleration along the $X$-axis. With $V T$ below the critical value (20 mm, in this article), a uniform-height region in the middle of the plate is always obtained. Moreover, for the same stroke time and acceleration along the $X$-axis, almost the same final geometry of plates is obtained for different velocities along the $Y$-axis, as long as $V T$ is lower than the critical value.

3. With $V T$ below the critical value, increasing acceleration along the $X$-axis leads to a decreased thickness in the side and an increased thickness in the middle region. High acceleration has a limited effect on the final morphology of the plates.

4. With VT below the critical value, increasing the stroke time results in a decreased thickness in the side and an increased thickness in the middle region. A high stroke time has a limited effect on the final morphology of the plates.

5. The $M S$ surface roughness is introduced to evaluate the processing parameters. On the basis of the analysis of the $M S$ surface roughness, the optimal combinations of processing parameters can be found.

\section{ACKNOWLEDGMENTS}

The authors acknowledge the financial support from the Department of Energy (DE-FC07-00ID 13816) and National Science Foundation (NSF CTS-9901375).

\section{REFERENCES}

1. E.J. Lavernia and Y. Wu: Spray Atomization and Deposition, John Wiley \& Sons, Inc., New York, NY, 1996.

2. P.S. Grant: Progr. Mater. Sci., 1995, vol. 39, pp. 497-545.

3. C.Y. Tsao and N.J. Grant: Int. J. Powder Metall., 1994, vol. 30, pp. 323-33.

4. S. Annavarapu, D. Apelian, and A. Lawley: Metall. Trans. A, 1990, 21A, pp. 3237-56.

5. G. Hartmann, P.N. Hansen, and P.R. Sahm: in Modeling and Control of Casting and Welding Processes IV, A.F. Giamei and G.J. Abbaschian, eds., TMS, Warrendale, PA, 1988, pp. 915-21.

6. B.W. Oh and Z.H. Lee: Proc. Modeling of Casting and Solidification Process, Yonsei University, Yonsei, Korea, 1991, pp. 13-22

7. H.K. Seok, D.H. Yeo, K.H. Oh, H.I. Lee, and H.Y. Ra: Metall. Mater. Trans. B, 1998, vol. 29B, pp. 699-708.

8. P. Mathur, D. Apelian, and A. Lawley: Mater. Sci. Eng., 1991, vol. A142, pp. 261-76.

9. Y.J. Lin, J.E. Bobrow, D.R. White, and E.J. Lavernia: Metall. Mater. Trans. A, 2000, vol. 31A, pp. 2917-29.

10. H.K. Seok, D.H. Yeo, K.H. Oh, H.Y. Ra, D.S. Shin, and H.I. Lee: Proc. 3rd Int. Conf. on Spray Forming, Wales, United Kingdom, 1996, pp. 287-95.

11. B.C. Moon, Z.H. Lee, and E.J. Lavernia: J. Mater. Res., 2000, vol. 15.

12. E.A. Brandes and G.B. Brook: Smithells Metals Reference Book, Butterworths-Heinemann, Oxford, United Kingdom, 1992.

13. D.R. Lide: The CRC Chemistry and Physics Handbook, CRC Press, Ann Arbor, MI, 1995.

14. W. Cai and E.J. Lavernia: Metall. Mater. Trans. B, 1998, vol. 29B, pp. 1085-96.

15. E.L. Crow and K. Shimizu: Lognormal Distributions: Theory and Applications, Marcel Dekker, New York, NY, 1988, p. 2.

16. J.E. Smith and M.L. Jordan: J. Colloid. Sci., 1964, vol. 19, pp. 549-59.

17. A.H. Lefebvre: Atomizations and Spray, Taylor \& Francis, Bristol, PA, 1989 , p. 85.

18. A. Lawley: Atomization: the Production of Metal Powders, MPIF, Princeton, NJ, 1992, p. 74.

19. K. Lubanska: J. Met., 1970, vol. 22, pp. 45-49

20. Q. Xu, V.V. Gupta, and E.J. Lavernia: Metall. Mater. Trans. B, 1999, vol. 30B, pp. 527-39.

21. Q. Xu, V.V. Gupta, and E.J. Lavernia: Acta Metall., 2000, vol. 48, pp. 835-49. 